\title{
Move on up, it's time for change-mobile signals controlling photoperiod-dependent flowering
}

\author{
Yasushi Kobayashi and Detlef Weigel ${ }^{1}$ \\ Department of Molecular Biology, Max Planck Institute for Developmental Biology, D-72076, Tübingen, Germany
}

\begin{abstract}
Plants do not bloom randomly-but how do they know when and where to make flowers? Here, we review molecular mechanisms that integrate spatial and temporal information in day-length-dependent flowering. Primarily through genetic analyses in two species, Arabidopsis thaliana and rice, we today understand the essentials of two central issues in plant biology: how the appropriate photoperiod generates an inductive stimulus based on an external coincidence mechanism, and the nature of the mobile flowering signal, florigen, which relays photoperiod-dependent information from the leaf to the growing tip of the plant, the shoot apex.
\end{abstract}

We all love springtime, not least because flowers are everywhere. But how do plants know it is the right time to bloom? Just like us, plants can recognize the seasons. Among different indicators such as temperature and light, the increase in day length is the most robust telltale sign that spring is upon us, at least for those of us who do not live in the tropics. The ability to recognize and respond to changes in day length is known as photoperiodism and is common to both plants and animals. In this review, we will focus on events downstream from the circadian clock that relay the photoperiodic signal from the site of perception, the leaves, to the shoot apex, where flowers are formed. Recent advances in this area have finally provided a molecular underpinning for two long-standing tenets of plant biology, the external coincidence model and the florigen hypothesis.

\section{The discovery of photoperiodic control of flowering}

One of the first to recognize the importance of day length in flowering was the English botanist Arthur Henfrey (1852), who suggested that summer day length, which changes with latitude, is an important factor in deter-

[Keywords: Flowering; floral induction; photoperiod; CONSTANS; FLOWERING LOCUS T; Arabidopsis]

${ }^{1}$ Corresponding author.

E-MAIL weigel@weigelworld.org; FAX 49-7071-601-1412.

Article is online at http://www.genesdev.org/cgi/doi/10.1101/gad.1589007. mining where plants could grow. Some 50 years later, the French scientist Tournois (1912) found that both Humulus (hop) and Cannabis (hemp) flower precociously when kept in winter in a greenhouse supplemented with artificial light, in agreement with Henfrey's postulate. The German Klebs made similar observations with Sempervivum (house leek). Importantly, he realized that it was unlikely to be light quantity (as a nutritive factor, as he called it) but rather light duration (acting as a catalytic factor) that was critical in this process (summarized in Klebs 1913).

Despite Tournois' and Klebs' contributions, the discovery of day length as a crucial factor in flowering control is generally accredited to Wightman Garner and Harry Allard, scientists at the US Department of Agriculture. Garner and Allard (1920, 1923) were working on two practical problems. One was the question of why certain strains of soybeans often would initiate flowers more or less simultaneously, typically during the height of summer, even if farmers had spread out the sowing dates. The other related to a tobacco variety that had spontaneously arisen in the field. This strain, appropriately called "Maryland Mammoth," would grow very tall, yielding nearly 100 leaves, whereas normal tobacco plants switch to making flowers with only $\sim 20$ leaves. The issue here was that this variety did not live up to its full commercial potential, because the delay in flowering often caused Maryland Mammoth plants to succumb to frost before they had produced any seeds, making it difficult to propagate the strain.

The reason that Garner and Allard are remembered for being the first to clearly demonstrate the effect of photoperiod is that they performed controlled experiments. Starting with Biloxi soybean and Maryland Mammoth tobacco plants raised in pots, they exposed one set to natural outdoors conditions, but artificially shortened the day for the other group by moving them into a windowless shed in the afternoon, returning them to the field in the morning. This simple trick greatly accelerated the flowering response of both soybean and tobacco, leading Garner and Allard $(1920,1923)$ to deduce that these strains only flowered when day length fell under a certain threshold. This neatly explained why the exact 
time point of sowing has not much influence on when Biloxi soybeans start to make flowers or why Maryland Mammoth tobacco produce flowers only late in fall.

It did not take much longer for scientists to realize that flowering plants generally belong to three categories: those in which short days promote flowering or long days prevent it, those in which long days promote flowering or short days prevent it, and a group that does not care either way. These categories are known as shortday, long-day, and day-neutral plants, and are often distinguished further by the adjectives obligate and facultative, depending on whether the corresponding day length requirement is absolute (for review, see Thomas and Vince-Prue 1997). Furthermore, the terms "short days" and "long days" are relative-they merely indicate that one plant will flower when day length falls below its critical photoperiod, while another flowers once it rises above its own specific threshold. Hence, the short day of one plant may actually not be different in length from the long day of another plant.

\section{How plants (and other organisms) measure the length of day and night}

The discovery of photoperiodism raised several questions, including which molecules the plant uses to sense light and how these molecules help the plant to measure day length. Perhaps the simplest mechanism one can envision is modeled on an hourglass. For example, every time the light is switched on, a substance that prevents flowering above a certain level begins to accumulate. If this substance is in addition degraded again every night, it will only stay under the critical threshold and hence permit flowering if days are sufficiently short.

Erwin Bünning was the first to propose that plants might use a more sophisticated mechanism. His model was based on the known fact that bean seedlings show a pronounced daily rhythm in leaf movement and that this rhythm is maintained even after plants have been moved to permanent darkness. Key insights of Bünning and his collaborator Kurt Stern (Bünning and Stern 1930) were that the red component of the light spectrum causes the movement of different individual plants to be synchronous and that without the red light cue the period would slowly diverge from the normal $24 \mathrm{~h}$. Bünning correctly concluded that the "biological clock" of plants is partially independent of the daily light/dark cycle. He furthermore found that different strains of beans have endogenous rhythms that can be either shorter or longer than $24 \mathrm{~h}$, and, using crosses, he demonstrated a genetic basis for these differences.

Initially, Bünning thought that the movement of bean leaves had no adaptive value, but rather was just a convenient indicator of what we call today the circadian clock, to reflect its role in time measurement on a $24-\mathrm{h}$ scale. He did, however, believe that an interaction of the endogenous rhythm with external rhythms would be important for plant development. Bünning (1936) subsequently came to appreciate that photoperiodic control of flowering could be a perfect example for where such an interaction might occur. According to the Bünning hypothesis, a 24-h day is divided into a photophile (lightsensitive) and scotophile (dark-sensitive) phase, and the rhythmic alternation of the two is prescribed by an endogenous circadian oscillator. The presence or absence of external light during either phase would tell a plant whether it was exposed to a short or a long day (Fig. 1). The circumstances of the time prevented the ideas laid out by Bünning, an avowed Social Democrat opposed to the Nazis, from gaining immediate and wide acceptance.

From the late 1950s, Colin Pittendrigh, Professor at Princeton and Stanford, became a great advocate of Bünning's work. Pittendrigh, who was working with insects, formalized and expanded the Bünning hypothesis, coining the term "external coincidence," since the model posits that the photoperiodic signal is only generated when a specific external phase (light or dark) coincides with the appropriate internal phase of the 24-h cycle. Importantly, light has a dual role in this model: It entrains the circadian oscillation of light- and dark-sensitive phases, and it is directly required for the production of the signal (Pittendrigh 1960). In contrast to a simple hourglass mechanism, what matters in the external co-
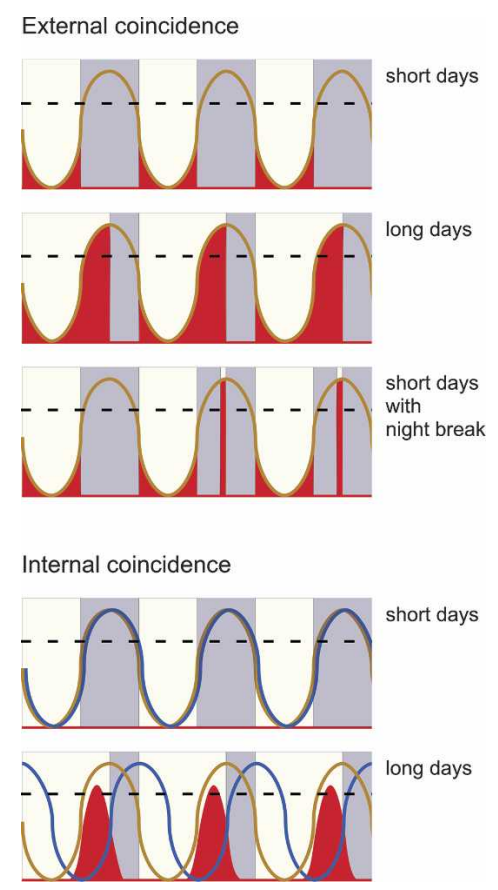

Figure 1. Two models to explain photoperiodic responses in short-day plants. In the external coincidence model, light entrains a periodic function (ochre). Light also causes the production of a repressor (red) directly proportionate to this function. Thus, even short night breaks, if given at the correct time, can lead to the repressor surpassing a critical threshold (dashed line). In the internal coincidence model, light signals (e.g., lights on/ off) entrain two different periodic functions. If one function (ochre) leads to production of a repressor, but the other function (blue) inhibits it, it will depend on their relative overlap whether the repressor (red) will reach a critical threshold. Since the details can vary considerably, it is difficult to predict the effects of night breaks on an internal coincidence mechanism. 
incidence model is not the duration of light, but rather the presence of light at specific times during the 24-h cycle. This was shown as early as the 1930s both by using light/dark cycles that were longer or shorter than the normal $24 \mathrm{~h}$ and by complex cycles in which dark periods were interrupted by brief light pulses (Fig. 1; Hamner and Bonner 1938; Harder and Bode 1943; Pittendrigh and Minis 1964). In some cases, night breaks as short as $1 \mathrm{~min}$ are effective in preventing flowering of short-day plants, a finding incompatible with a simple hourglass model (Hamner and Bonner 1938).

Despite the success of the external coincidence model in explaining the effects of different light treatments, Pittendrigh (1972) realized that a related mechanism, relying only on internal rhythms, might be exploited as well in photoperiod measurement. In the internal coincidence model, external cues-e.g., lights on and lights off-entrain two different oscillations. Only when these oscillations are in synchrony is the inductive or repressive signal triggered (Fig. 1).

\section{Where plants measure the length of day and night}

Having discussed insightful studies from the premolecular era that allowed many inferences about how plants measure day length, we now turn to the question of where this process occurs. Flowers form at the growing tip of the plant, the shoot apex. Because the delicate shoot apex often has a protective covering of leaves, it might not be the best place for plants to interpret ambient light conditions. Julius Sachs-Professor of Botany in Bonn, Freiburg, and Würzburg, and one of the mentors of Klebs-had conducted experiments in which he darkened parts of a plant, and from this he concluded that leaves in the light produce flower-forming substances (summarized in Sachs 1865). This was demonstrated directly in the 1930s by exposing only leaves, but not the shoot apex, to flower-inducing photoperiods (Knott 1934). The Russian botanist Mikhail Chailakhyan formalized this as the florigen hypothesis, with florigen being defined as a substance that is generated in leaves under inductive photoperiods and translocated from leaves to the shoot apex (Chailakhyan 1936a,b, 1937). The florigen hypothesis was soon confirmed experimentally, by studies in a variety of systems (for review, see Thomas and Vince-Prue 1997). For example, in Xanthium (cocklebur), exposing a single leaf to one short-day cycle is sufficient to induce flowering, even when plants are subsequently returned to noninductive long days (Naylor 1941). Naylor, as well as others, noticed that initiation of flowers is much more robust after noninduced leaves are removed, suggesting that stimulating export of photosynthetic assimilates through the phloem stream causes also increased export of florigen from the induced leaf. It was later demonstrated that florigen indeed moves with about the same velocity as photosynthetic assimilates, further supporting the notion that the phloem portion of the plant vasculature is the conduit for florigen (e.g., see King et al. 1968).

But the most stringent tests of the florigen hypothesis were those that employed grafting of induced leaves onto noninduced plants. Georg Melchers (1937), who, like Bünning, spent much of his career in the Southern German town of Tübingen, showed that leaves of both shortday- and long-day-requiring strains of Hyoscyamus (henbane) produce a signal that can cause a biennial Hyoscyamus strain to flower in the first year (biennial plants normally have an obligate requirement for passing through winter before they will flower). A final example from this era is provided by the work of Jan Zeevaart (1958), who later collaborated with Melchers' student Anton Lang (e.g., see Lang and Melchers 1948). Zeevaart (1958) showed that an induced leaf of Perilla (shiso, an herb widely used in many East and Southeast Asian cuisines) retains its ability to cause flowering of a recipient plant, even if it had been moved from inducing to noninducing conditions 3 mo ago. This is, however, not universal. The induced leaves of Ipomoea (Pharbitis) nil (morning glory) produce florigen only for a few days in the absence of a continuous stimulus (Imamura 1967).

\section{Genetics to the rescue}

Despite the initial rapid advances in understanding central features of photoperiod measurements and signaling, further attempts at isolating florigen or revealing its molecular nature failed. This led some to propose that florigen was not a single substance, but rather a mixture of different molecules. Some went so far to suggest that it might even involve an electric signal (Karege et al. 1982).

Most of the essential components are now known, largely thanks to pioneering genetic analyses done with Arabidopsis thaliana, a facultative long-day plant (Napp-Zinn 1969). Popular laboratory strains flower within a few weeks under long days, but much later in short days. While variation in flowering behavior of naturally occurring $A$. thaliana strains had already been noticed by Friedrich Laibach (1951), George Rédei (1962) was the first to isolate flowering mutants in a defined background. Loss-of-function mutations at three loci, CONSTANS (CO), GIGANTEA (GI), and LUMINIDEPENDENS $(L D)$, cause plants to flower later than the standard strain under inductive long days. Rédei had noticed that the co line flowers at about the same time in long and short days, which was the reason he christened the mutant constans. Rédei was, however, more interested in the fact that the late-flowering strains appeared to be more vigorous (reflected by the name gigantea for one of the other mutants), and he did not further exploit them to dissect the physiology of flowering. This was left to Maarten Koornneef et al. (1991), who performed the first large-scale genetic screens for mutants with abnormal flowering behavior. Koornneef used less colorful names than Rédei, and named all of them "f" (for flowering) followed by one or two additional letters $(f c a, f d$, $f e, f h a, f p a, f t, f_{v e}, f w a$, and $f y \mid$. Because some journals insist that one spell out gene names, we later invented the name FLOWERING LOCUS $T$ for the FT gene (Kardailsky et al. 1999). In contrast to Rédei, Koornneef used these mutants to focus on the control of flowering 
time. He observed that several flower much later than the wild type in long days, but that they are about as late as wild type under noninductive short days. He therefore postulated that the $C O, F T$, and GI genes, and possibly also FHA, are specifically involved in the perception of the photoperiod signal (Koornneef et al. 1991), which we today know from molecular analyses to be correct.

Koornneef isolated additional mutants impaired in several different processes, ranging from light and hormone response to floral organ formation, and his successes inspired many others to conduct their own mutant hunts. In addition to morphological traits, several scientists began to exploit reporter genes, and one of these screens led to the isolation of mutants defective in the circadian clock (Millar et al. 1995). Many clock genes have in the meantime been cloned, with additional factors identified by reverse genetics, and their functional analysis, coupled with whole-genome studies, has allowed the development of sophisticated models of circadian regulation in $A$. thaliana (Locke et al. 2006; Zeilinger et al. 2006). For a detailed discussion of the circadian clock, the reader is referred to recent reviews (Gardner et al. 2006; McClung 2006).

\section{Molecular basis of the external coincidence model}

It is primarily through the analysis of two genes that we understand today the molecular basis of the external coincidence model in plants: $C O$, which encodes a B-box zinc finger protein (Putterill et al. 1995), and FT, which encodes a small transcription cofactor (Fig. 2; Kardailsky et al. 1999; Kobayashi et al. 1999).

Although the exact biochemical function of CO protein is not entirely understood, CO is an important regulator of FT mRNA expression (Kobayashi et al. 1999; Samach et al. 2000; Suárez-López et al. 2001; Yanovsky and Kay 2002; An et al. 2004). Genome-wide analyses with loss-of-function mutants have confirmed FT as the major early target of CO (Wigge et al. 2005). CO on its own does not bind DNA, but it likely acts as part of a CCAAT-box-binding complex involving HAP proteins
(Ben-Naim et al. 2006; Wenkel et al. 2006; Cai et al. 2007). CO is probably recruited to the FT promoter, based on experiments with an overexpressed version of CO that can be post-translationally controlled. However, because several other potential direct targets identified in this study (Samach et al. 2000) could not be confirmed in analyses of co mutants (Wigge et al. 2005), additional experiments are needed to demonstrate unambiguously that FT is directly regulated by CO. FT is known to be a direct target of FLOWERING LOCUS C (FLC) and SHORT VEGETATIVE PHASE (SVP), transcriptional repressors that mediate the effects of exposure to winterlike conditions or to more modest changes in ambient temperature (Helliwell et al. 2006; Searle et al. 2006; Lee et al. 2007). In addition, chromatin modification appears to play an important role in preventing inappropriate $F T$ expression (Piñeiro et al. 2003; Takada and Goto 2003; Germann et al. 2006; Turck et al. 2007).

When the Weigel and Araki groups (Kardailsky et al. 1999; Kobayashi et al. 1999/ cloned the FT gene, both overlooked that FT mRNA abundance has a circadian cycle. Since $C O$ mRNA had been reported to accumulate at the shoot apex, where flowers are produced (Simon et al. 1996), the focus at the time was on processes thought to be much downstream from the photoperiodic signal. It was therefore a major advance when it was discovered that FT mRNA expression is not only much higher in long days, but also has a circadian pattern, with peak levels during the second half of a 24-h cycle (Harmer et al. 2000; Suárez-López et al. 2001). There is very little FT expression in short days, but upon transfer from short to inductive long days, FT is immediately induced in a $C O$ dependent manner, and returning plants to short days causes FT expression to subside within a day, indicating a very immediate effect of day length on FT mRNA accumulation (Imaizumi et al. 2003; Corbesier et al. 2007).

In contrast to $F T, C O$ mRNA is easily detected in both long and short days. Its abundance cycles regardless of day length, with a prominent peak in the night following either a long or a short day, and an earlier shoulder in the afternoon only in long days (Fig. 2; Suárez-López et al. 2001). The observation that $C O$ mRNA expression does

Figure 2. Photoperiod-dependent activation of FT mRNA expression in the leaf of the long-day plant A. thaliana. CDF1 mRNA is expressed highly at the beginning of the day. FKF1 protein is only active in the light and causes destabilization of CDF1 protein, so that in long days, CDF1 protein is at very low levels during the second half of the light phase. Since CDF1 represses CO mRNA expression, this in turn allows for an earlier increase of $C O$ mRNA levels in long days. CO protein is only stable in the light; hence it accumulates only in long days. It in turn activates $F T$ mRNA expression.

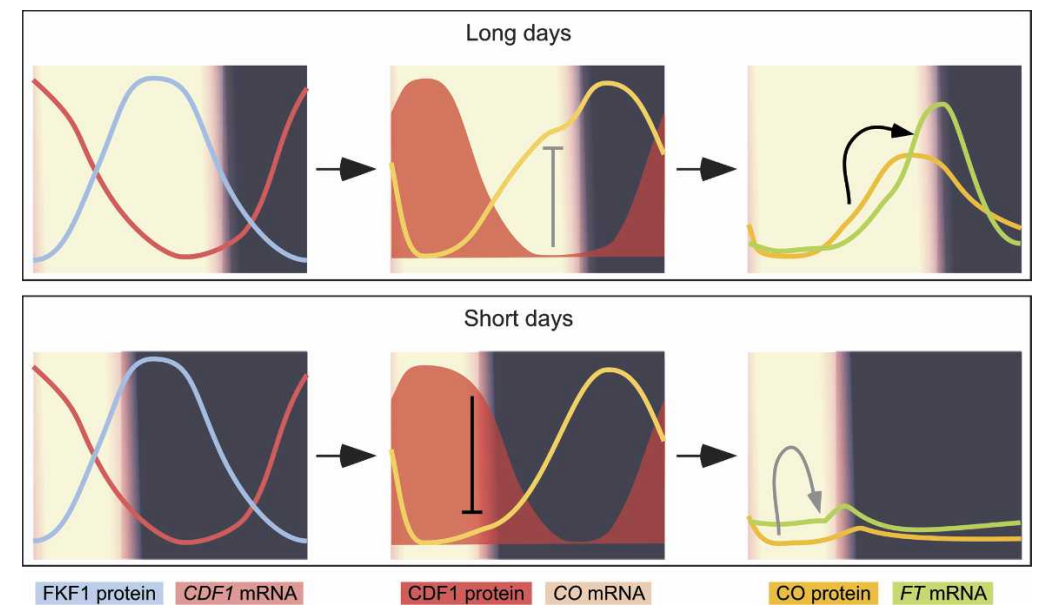


not automatically lead to accumulation of FT mRNA suggested that the $C O / F T$ module might be at the heart of a molecular external coincidence mechanism. A first line of indirect evidence in support of this hypothesis was provided by Yanovsky and Kay (2002), who studied the toc1 (timing of $C A B$ expression 1) mutant, in which the period of the endogenous clock is shortened to $\sim 21 \mathrm{~h}$ compared with $\sim 24.5 \mathrm{~h}$ of the wild type. While many other clock mutations alter both the phase and level of CO mRNA expression (Suárez-López et al. 2001), toc1 affects only the phase angle of $C O$, such that $C O$ mRNA peaks earlier in short days and therefore in the light, while high levels of $C O$ mRNA are restricted to the dark in short-day grown wild-type plants (Yanovsky and Kay 2002). When the day-night cycle is shortened to $21 \mathrm{~h}$ and thus matched to the endogenous period in toc 1 mutants, the $C O$ pattern no longer differs from that in wild type and the short-day early flowering phenotype of toc1 is suppressed (Strayer et al. 2000; Yanovsky and Kay 2002). Additional, more sophisticated manipulations of length and structure of the light/dark cycle, similar to what had been used in the early days of studying the circadian clock (Nanda and Hamner 1958; Pittendrigh 1960), confirmed that bringing peak levels of $C O$ mRNA into the light phase promotes flowering of wild-type plants under short photoperiods (Roden et al. 2002).

That FT is only induced when high levels of $C O$ mRNA are present in the light pointed to post-transcriptional regulation of $C O$ activity. In an elegant series of experiments, George Coupland and colleagues (Valverde et al. 2004) demonstrated that far red and blue light, which are respectively perceived by phytochrome A and cryptochrome 2 (the latter encoded by the flowering time gene FHA; Guo et al. 1998), regulate the stability of CO protein through inhibition of proteasome-dependent $\mathrm{CO}$ degradation. Thus, the light-sensitive flowering regulator that Bünning (1936) proposed to be produced with a circadian rhythm does indeed exist: It is the CO protein. In the dark, CO is likely recruited to the proteasome by SUPPRESSOR OF PHYA-105 (SPA) proteins, which in turn interact with the E3 ubiquitin ligase CONSTITUTIVE PHOTOMORPHOGENIC 1 (COP1) (Laubinger et al. 2004, 2006).

Interestingly, light of another quality, red light, which is perceived by phytochrome $\mathrm{B}$, promotes, rather than inhibits, degradation of $\mathrm{CO}$, and thereby delays flowering (Mockler et al. 2003; Valverde et al. 2004). The mechanism remains unclear since misexpression experiments have suggested a nonautonomous effect of phytochrome B on CO (Endo et al. 2005). Finally, the PHYTOCHROME AND FLOWERING TIME 1 (PFT1) protein has been proposed to specifically mediate the effects of phytochrome B on FT independently of CO (Cerdán and Chory 2003). Since PFT1 has recently been identified as a subunit of Mediator, a multiprotein complex that has a general role in transcriptional regulation (Bäckström et al. 2007), this hypothesis may need to be revisited.

The function of $C O$ and FT is likely to be universal, since their orthologs in rice, Heading-date 1 (Hd1, also known as Photoperiod Sensitivity 1, Se1) and Hd3a, play very similar roles. Not only is rice, a grass, a distant relative of $A$. thaliana among flowering plants, but it is also a short-day plant. The groups of Masahiro Yano, Ko Shimamoto, and Takeshi Izawa (Yano et al. 2000; Izawa et al. 2002; Kojima et al. 2002; Hayama et al. 2003) showed that, similar to the situation in A. thaliana, $H d 1 / S e 1$ and $H d 3 a$ promote flowering (or heading as it is called in rice) in response to inductive photoperiods, in this case short days. In addition to activating $\mathrm{Hd} 3 \mathrm{a}$ under inductive conditions, $\mathrm{Hd} 1 / \mathrm{Se} 1$ represses $\mathrm{Hd} 3 \mathrm{a}$ under noninductive conditions. Plants with compromised Hd1/Se1 activity thus flower later than wild type in short days (under inductive conditions), but earlier in long days (under noninductive conditions) (Fig. 3; Yano et al. 2000). The situation might be similar in $A$. thaliana, as some investigators, though not all, found $c o$ mutants to flower a bit earlier than wild type in short days (Rédei 1962; Koornneef et al. 1991; Reeves and Coupland 2001).

Intriguingly, the repressive function of $\mathrm{Hd} 1 / \mathrm{Se} 1 \mathrm{re}$ quires the red-light receptor phytochrome B. Loss of phytochrome B activity therefore leads to early flowering, similar to the effects of phytochrome B mutations in $A$. thaliana (Reed et al. 1993; Ishikawa et al. 2005), albeit for a different reason: While phytochrome B antagonizes the activation of FT by $C O$ in $A$. thaliana /Cerdán and Chory 2003; Halliday et al. 2003; Valverde et al. 2004; Endo et al. 2005), it stimulates the repression of $H d 3 a$ by

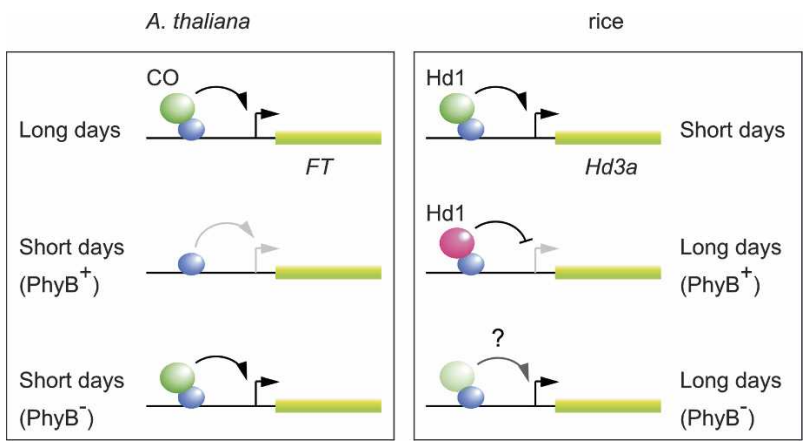

Figure 3. Comparison of the function of the orthologs $\mathrm{CO}$ and Hd1. A. thaliana is a long-day plant, while rice is a short-day plant. In both species, the orthologs $F T / H d 3 a$ act downstream from $\mathrm{CO} / \mathrm{Hd} 1$ to promote flowering. In A. thaliana, CO seems to be largely dispensable in noninductive short days (because there is little or no protein), while in rice, Hd1 is actively repressing $H d 3 a$ in noninductive long days (as deduced from genetic analyses). Mutational inactivation of the phytochrome B (PhyB) photoreceptor causes early flowering in noninductive conditions in both species, but for different reasons. In $A$. thaliana phy $B$ mutants, CO protein is stabilized and can activate $F T$; in rice phyB mutants, $\mathrm{Hd} 1$ activity is no longer modified by phytochrome $\mathrm{B}$, which normally turns $\mathrm{Hd} 1$ into a repressor (indicated by a different color); flowering is now accelerated, because repression is relieved and, perhaps in addition, $\mathrm{Hd} 1$ activates Hd3a. For simplicity, it is shown here that $\mathrm{CO}$ and $\mathrm{Hd} 1$ are recruited by other proteins (possibly HAP factors) to the $F T$ and $H d 3 a$ promoters, although this has not been formally demonstrated. Similarly, it is not known yet whether Hdl protein itself is modified by phytochrome $\mathrm{B}$. 
Hd1/Se1 in rice (Fig. 3; Ishikawa et al. 2005). A further major difference between the two species emerged from the discovery of Early heading date 1 (Ehd1), which encodes an apparent transcription factor with a GARP DNA-binding domain. Ehd1, which is expressed independently of $H d 1 / \mathrm{Se} 1$, is a positive regulator of $H d 3 a$ and other FT-like genes in rice, but has no obvious counterpart in the $A$. thaliana genome (Doi et al. 2004).

As alluded to earlier, $C O$ expression profiles are similar but not identical under long and short days, with substantial levels of $C O$ mRNA detected earlier and in the light when photoperiods are long (Suárez-López et al. 2001). The initial shoulder that precedes the later peak of $C O$ mRNA in long days requires activity of FLAVINBINDING, KELCH REPEAT, F-BOX 1 (FKF1), which itself is transcriptionally regulated by the circadian clock (Fig. 2). FKF1 mRNA has a rather narrow peak of expression, which is in the second half of a long day, but toward the end of a short day. The FKF1 protein, a blue-light receptor, shows a broader peak, resulting in FKF1 being present during much of the second half of the light phase in long days, but only during the dark phase in short days (Imaizumi et al. 2003). Regulation of FKF1 activity by light provides a mechanism for how FKF1 promotes the daytime shoulder of $C O$ mRNA in long days. Light-activated FKF1 affects $C O$ mRNA accumulation by destabilizing CYCLING DOF FACTOR 1 (CDF1), a direct repressor of CO transcription (Imaizumi et al. 2005). This occurs most likely through an SCF complex that includes FKF1 as specificity component (Han et al. 2004; Takahashi et al. 2004). Whether CDF1 and its homologs are the only factors mediating FKF1 activity still needs to be demonstrated, since so far only partial CDF lossof-function lines with rather weak phenotypes have been examined (Imaizumi et al. 2005). Among other factors that have less precisely defined roles but are also important for shaping the $C O$ mRNA profiles is RED AND FAR-RED INSENSITIVE 2 (RFI2), a RING-domain zinc finger protein (Chen and Ni 2006). In summary, photoperiod controls both the mRNA expression pattern of $\mathrm{CO}$ and the stability of CO protein, even though the Bünning model would have required only one level of regulation.

\section{Molecular basis of florigen}

Now that we have discussed the molecular essence of the external coincidence model, we turn to the second big question in flowering biology: the molecular nature of florigen. Grafting experiments demonstrated that $C O$ acts upstream of the mobile signal, making the $C O$ target FT an excellent candidate for florigen (An et al. 2004; Ayre and Turgeon 2004). The FT promoter is active in the companion cells of the phloem, and in situ hybridization in a mutant with derepressed FT expression confirmed that the transcript accumulates in the phloem (Takada and Goto 2003; An et al. 2004). FT expression in phloem companion cells is essential for its function, as recently shown by tissue-specific inactivation of FT mRNA using artificial microRNAs (Mathieu et al. 2007).
Consultation of an expression atlas based on microarray experiments confirmed that FT mRNA is more abundant in leaves, particularly in cotyledons and the distal portion of older leaves, than at the shoot apex (Wigge et al. 2005).

Different from $F T$, tissue-specific overexpression experiments indicated that $C O$ is ineffective when present only at the shoot apex, while specific overexpression in the phloem of leaves has similar effects as ubiquitous overexpression (An et al. 2004; Ayre and Turgeon 2004; Corbesier et al. 2007). In stark contrast, tissue-specific overexpression of FT causes early flowering, regardless of whether this occurs in the phloem of leaves and stem or at the shoot apex (An et al. 2004), which was the first result that immediately suggested $F T$ exerting its role at the shoot apex.

The initial sequence analysis of FT had not been very revealing, as FT was found to encode a small globular protein with structural similarity to a variety of enzyme inhibitors in fungi and animals, including Raf kinase inhibitor protein (Kardailsky et al. 1999; Kobayashi et al. 1999; Ahn et al. 2006). FT might play a general role as a molecular scaffold (Pnueli et al. 2001), but the best understood function is as a transcriptional cofactor, interacting directly with the bZIP protein FD. In contrast to FT, FD mRNA is found only at the shoot apex, with a moderate increase in expression levels upon photoperiodic induction that appears to be FT independent (Abe et al. 2005; Wigge et al. 2005). At the shoot apex, FD likely recruits FT to the promoter of $A P E T A L A 1(A P 1)$, an important regulator of flower fate, although this conclusion is based on experiments with FD-overexpressing plants, and the interaction found was fairly weak. The role of FT as a transcriptional cofactor is, however, supported by the effects of fusing it to the heterologous VP16 activation domain (Wigge et al. 2005).

The finding that photoperiod-activated $\mathrm{CO}$ regulates FT transcription in the phloem of leaves, but FT protein acts at the shoot apex, suggested that FT mRNA or protein is translocated from the leaf to the shoot apex, and that one of them is the mobile florigen signal. The companion cells, in which FT is transcribed, directly contact the sieve elements, which form the conducting tissue of the phloem. It has been known for several years that small globular proteins such as free green fluorescent protein (GFP) not only readily enter sieve elements from the companion cells (most likely through intercellular channels called plasmodesmata), but also that they are transported across large distances through the phloem and can be unloaded from the phloem into surrounding tissue (Imlau et al. 1999; Stadler et al. 2005). At 27 kDa, GFP is considerably larger than FT, a globular protein of $20 \mathrm{kDa}$ (Ahn et al. 2006), suggesting that FT moves between cells at least as well as free GFP. Taken together, the simplest scenario is that FT protein itself constitutes the long-distance signal (Abe et al. 2005; Wigge et al. 2005).

Unfortunately, there was some initial confusion because of erroneous reports of long-distance trafficking of FT mRNA (discussed in Zeevaart 2006). In a study that 
met with initial skepticism because of this earlier report, and that needs to be appreciated more widely, Eliezer Lifschitz et al. (2006) were the first to address directly the question of FT mRNA versus protein as florigenic substance, employing grafting techniques. The SINGLE FLOWER TRUSS (SFT) gene of tomato is the FT ortho$\log$, and even though tomato is day neutral, sft mutants flower very late. Grafts from SFT-overexpressing plants (albeit not from wild-type plants) consistently and strongly rescued the flowering defect of $s f$ mutants. Since no SFT mRNA could be detected in the recipient, these authors concluded that either SFT protein itself is the mobile signal or that SFT elicits a secondary mobile signal (Lifschitz et al. 2006). In tomato, the FD ortholog SPBG is expressed widely (Pnueli et al. 2001), and such a secondary signal is a distinct possibility. In $A$. thaliana, however, this seems less likely, since FT appears to act directly at the shoot apex. Importantly, Lifschitz et al. (2006) also demonstrated the universality of the systemic signal, by showing that a graft of tomato overexpressing SFT could accelerate flowering in the classic Maryland Mammoth variety of tobacco, thereby reproducing, using modern tools, the findings of Melchers (1937) with henbane.

A string of recent papers has explored the molecular basis of the florigen signal in additional detail (Corbesier et al. 2007; Jaeger and Wigge 2007; Lin et al. 2007; Mathieu et al. 2007; Tamaki et al. 2007). Two of these studies (Jaeger and Wigge 2007; Tanaki et al. 2007) even claim to have demonstrated movement of FT protein from leaves to the shoot apex, even though direct experimental evidence has not been produced. Nevertheless, together with the previous findings (Abe et al. 2005; Wigge et al. 2005; Lifschitz et al. 2006), the arguments for FT protein (or its orthologs) being the long-distance signal are now quite strong.

Several investigators made use of lines that overexpressed FT fusion proteins in phloem companion cells. Coupland and colleagues (Corbesier et al. 2007) showed that an FT-GFP fusion protein in A. thaliana could move across a graft junction from the shoot to the root, in line with known properties of other GFP fusion proteins. However, in contrast to most GFP fusions, and similar to free GFP alone, FT-GFP can be unloaded from the phloem near the shoot apex (Stadler et al. 2005; Corbesier et al. 2007). Although even the overexpressed FTGFP could not be detected in the entire domain where the FT partner FD is expressed, the effects on flowering suggested that protein below the detection threshold was present throughout the shoot apical meristem /Corbesier et al. 2007). Export from the phloem was also demonstrated by Jaeger and Wigge (2007), using a fusion of FT to a small Myc tag; importantly, export from the phloem was prevented when the FT-Myc protein was directed to the nucleus with a heterologous nuclear localization signal. This finding is consistent with a general feature of many plant proteins, for which trafficking to adjacent cells is only prevented by efficient subcellular targeting, as proposed by $\mathrm{Wu}$ et al. (2003) and recently directly demonstrated for the SHORTROOT transcription factor
(Cui et al. 2007). Markus Schmid and colleagues (Mathieu et al. 2007) also trapped FT in phloem companion cells by fusing it to a nuclearly localized triple-GFP protein. Exploiting transgenically expressed tobacco etch virus (TEV) protease and a TEV protease recognition site engineered into this fusion, they could then release FT from this much larger precursor, which in turn caused early flowering. Similar conclusions regarding the export of an Hd3a-GFP fusion from the phloem were reached by Shimamoto's group (Tamaki et al. 2007) using rice. In this case, the fusion appeared to travel considerably further than in A. thaliana; however, as the authors duly note, free GFP shows a similar movement behavior, making it difficult to interpret the significance of their findings.

Change-of-function experiments, in which genes are misexpressed, have the disadvantages that expression levels are difficult to control and that one can never be quite sure that the promoter used is indeed completely silent in a specific tissue. Furthermore, all the experiments of "complementing" co and ft mutants with $C O$ and FT linked to a variety of different promoters actually led to much earlier flowering than seen in wild type. As already discussed, grafting experiments provide a more stringent assay for long-distance movement (An et al. 2004; Ayre and Turgeon 2004; Lifschitz et al. 2006; Corbesier et al. 2007). This route was also taken by the laboratory of Bill Lucas (Jorgensen et al. 1998), who has a long-standing interest in long-distance signaling, particularly by RNA molecules. The Lucas group (Lin et al. 2007) exploited the graft compatibility of two cucurbit species with different photoperiodic requirements for flowering. Their approach was particularly elegant, because sequence differences between the two species allowed differential detection of host and donor FT proteins after grafting. Using mass spectrometry, Lin et al. (2007) found FT protein from the donor in the phloem sap of the host, while this was not the case for FT mRNA. Importantly, similar to classic grafting experiments, induction of flowering in this system did not require overexpression in the donor. FT protein has also been detected by mass spectrometry in phloem sap of Brassica napus (rapeseed), the caveat being that these experiments were performed on inflorescence stems; that is, long after the plants had been stably induced to flower (Giavalisco et al. 2006)

In conclusion, while it so far has not been possible to directly identify FT protein that has been produced in leaves in the very cells at the shoot apex that also express its partner FD (an admittedly technically very challenging experiment), little doubt remains that FT (along with paralogs such as TSF; Michaels et al. 2005; Yamaguchi et al. 2005; Mathieu et al. 2007) is a major component of florigen. It is difficult to exclude, and indeed is perhaps likely, that other molecules appear in supporting roles. For example, several microRNAs (miRNAs) function in flowering control (e.g., see Aukerman and Sakai 2003; Schmid et al. 2003; Chen 2004; Schwab et al. 2005). While there is not yet any experimental evidence for long-range action of these miRNAs, 
some of them have been detected in phloem sap as well (Yoo et al. 2004).

\section{Molecular events at the shoot apex}

In $A$. thaliana, FT and FD are characterized by complementary expression patterns. FT expression is activated in a day-length-dependent manner, but does not provide regional specificity for flower initiation, since it is activated primarily in leaves. Positional information for flower formation requires $F D$, which is expressed at the shoot apex, albeit largely independently of inductive photoperiods. The outcome is that through the interaction of FT and FD proteins, flowers are formed at the right time, in the right place (Abe et al. 2005; Wigge et al. 2005).

How, then, does the FT/FD complex control the formation of flowers, which start out as groups of undifferentiated cells at the flanks of the shoot apical meristem? The only direct target of this complex proposed so far is AP1 (Wigge et al. 2005). As pointed out by Searle et al. (2006), expression of $A P 1$ is a relatively late event during floral induction, preceded by the activation of several other positive floral regulators, such as FRUITFULL (FUL), SUPPRESSOR OF OVEREXPRESSION OF CO 1 (SOC1, also known as AGAMOUS-LIKE 20 [AGL20]), its paralog $A G L 42$, and $A G L 24$, all of which like $A P 1$ encode MADS domain proteins. Apart from delayed activation of these genes at the shoot apex of $f t$ or $f d$ mutants, several are affected by misexpression of FT or FD (Yu et al. 2002; Schmid et al. 2003; Abe et al. 2005; Moon et al. 2005; Teper-Bamnolker and Samach 2005; Wigge et al. 2005; Searle et al. 2006). Many of these proteins interact with each other, as well as with SVP, a MADS domain protein that represses flowering (de Folter et al. 2005).

The effects of FT/FD on both early and late flowering activators at the shoot apex suggest a feed-forward mechanism, in which activation of early factors such as SOC1 enhances the direct activation of later factors such as AP1. A feed-forward mechanism, with FT/FD affecting expression of late targets such as AP1 both directly and indirectly through SOC1, would explain the relatively strong effect of $\operatorname{soc} 1$ mutations in a $f t$ background (Moon et al. 2005; Yoo et al. 2005). Intriguingly, negative feedback of AP1 on SOC1, AGL24, and SVP expression contributes to the formation of normal flower primordia, even though these effects are relatively modest (Yu et al. 2004; Liu et al. 2007).

A similar theme of dual levels of interconnected regulation is apparent in the roles of the floral repressor FLC, which mediates the effects of winter-like conditions. FLC counteracts activation of FT by $C O$ in the leaf and, in addition, directly represses expression of the FT cofactor FD at the shoot apex (Searle et al. 2006). Finally, apart from being a target of FT at the shoot apex, as first shown by Schmid et al. (2003), SOC1 is also expressed in leaves, and it is negatively regulated by FLC at both sites (Borner et al. 2000; Lee et al. 2000; Samach et al. 2000; Hepworth et al. 2002; Schmid et al. 2003; Michaels et al.
2005; Helliwell et al. 2006; Searle et al. 2006). In leaves, SOC1 is regulated independently of $C O$ by the clock (Blázquez et al. 2002; Fujiwara et al. 2005; Wigge et al. 2005). Whether or how SOC1 in leaves might affect flowering is, however, unknown, since FT expression in leaves appears to be unaffected by loss of SOC1 activity (Lee et al. 2000; Moon et al. 2005).

Even in the absence of FT and FD activity, all the early apex regulators such as SOC1 are eventually activated, revealing a photoperiod-independent component of regulation. A good candidate for such a pathway is one that relies on gibberellin hormones, which not only regulate, for example, SOC1 (Borner et al. 2000; Blázquez et al. 2002; Moon et al. 2003), but also the flower meristem identity gene $L E A F Y(L F Y)$ (Blázquez et al. 1998). In contrast to FT, FD, SOC1, and so on, LFY activity is essential for the development of normal flowers, acting partially redundantly in flower formation with the $F T / F D /$ AP1 axis (Weigel et al. 1992; Ruiz-García et al. 1997; Abe et al. 2005; Wigge et al. 2005). While early studies suggested that $L F Y$ functions primarily in parallel with $F T$, it is now clear that LFY is both a target of the FT and the gibberellin pathways (Nilsson et al. 1998; Blázquez and Weigel 2000; Schmid et al. 2003; Eriksson et al. 2006). Furthermore, contrary to common wisdom, gibberellins have a clear effect on flowering in long days, although it is not known whether they also function downstream from the photoperiod pathway in A. thaliana, as suggested for other species (Pharis et al. 1987; Blázquez et al. 1998; Griffiths et al. 2006; King et al. 2006; Willige et al. 2007). The regulatory interactions described in this and earlier sections are summarized in Figure 4.

\section{Research into photoperiodic flowering-time to move on?}

While core aspects of how photoperiod is perceived and how the signal is relayed from the leaves to the shoot apex are known, by no means do we completely understand the flowering process. Many open questions remain. For example, early apex regulators such as $F D$, $S O C 1$, or FUL show a different pattern of expression from their targets $L F Y$ and $A P 1$. The latter are expressed specifically in flower primordia, while the early regulators are found also, or mainly, in the shoot apical meristem, with their exact spatial relationships not known in much detail. Application of sophisticated live-imaging techniques, as they have been used for the study of meristem regulators (e.g., see Heisler et al. 2005), is almost certain to provide important new insights.

Another powerful approach is the manipulation of the spatial distribution of gene activity, but this has so far been mostly achieved by tissue-specific overexpression, which almost always leads to gain-of-function phenotypes and thus confounds the interpretation of results. A more sensitive assay is the ablation of normal gene function in specific tissues or cells. A new and very effective tool for this purpose is available in the form of artificial miRNAs (amiRNAs) (Alvarez et al. 2006; Schwab et al. 2006), and these have already been employed to demon- 


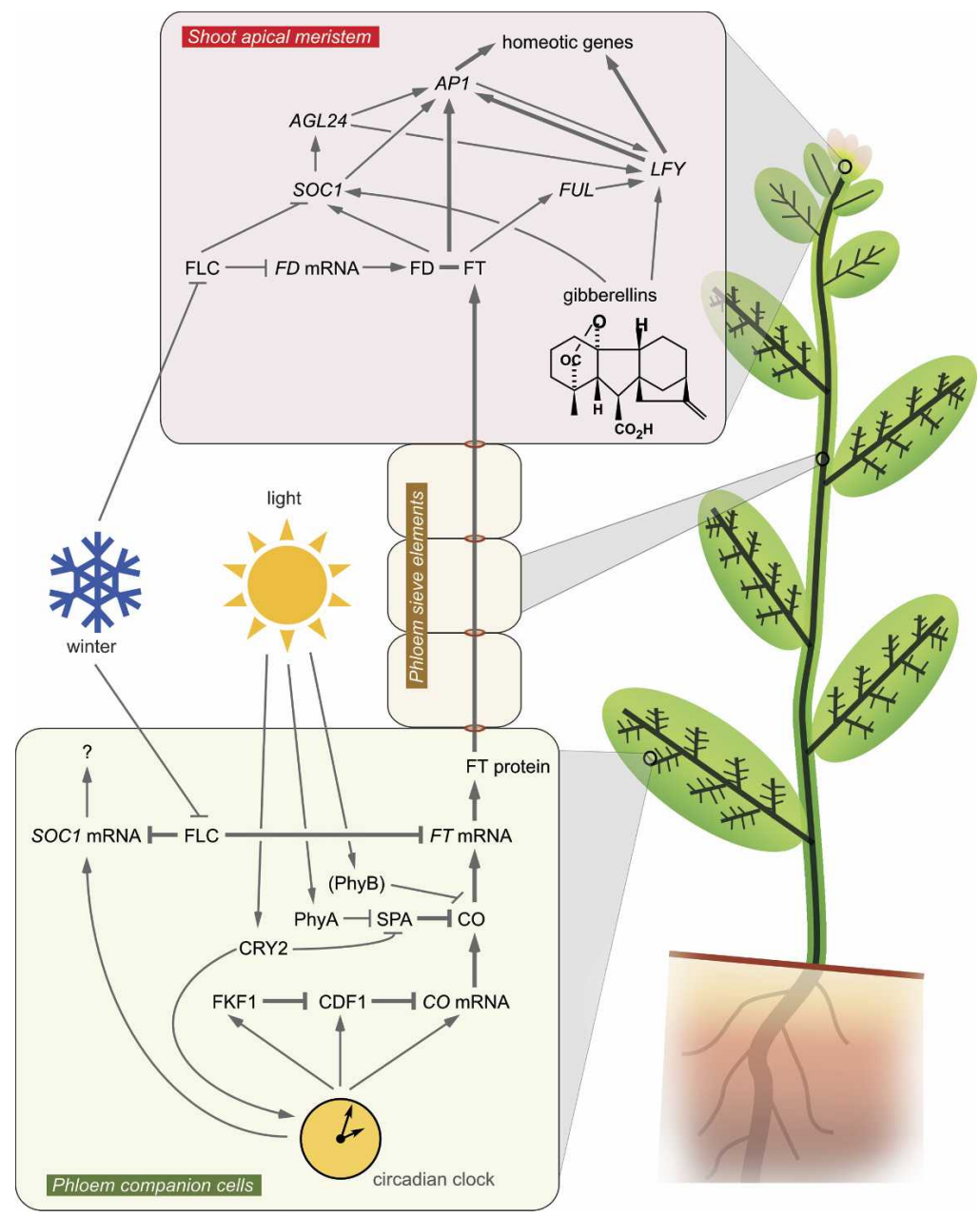

Figure 4. Key regulatory interactions in the leaf and at the shoot apex of $A$. thaliana. Direct interactions are indicated by bold lines (regulation of mRNA levels refers to transcriptional control). Light has a dual role in controlling the clock (for simplicity, only one line from the CRY2 photoreceptor is drawn) and CO protein stability. PhyB is shown in parentheses, to indicate that this interaction might not be cell autonomous. The schematic plant on the right illustrates the spatial relationships between the different tissues. Dark lines symbolize the vasculature. There is cellular continuity from the leaf to the shoot apex, provided by intercellular connections of plasmodesmata, shown as brown circles on the left. During the vegetative phase, the shoot apical meristem produces leaves. After flowering has been induced, it switches to the formation of flowers. strate that FT and TSF not only can function, when overexpressed, in phloem companion cells (An et al. 2004; Abe et al. 2005), but that they also, and perhaps more importantly, are required in these cells (Mathieu et al. 2007). Extension of this approach would be rather useful to formally demonstrate that clock components upstream of $C O$, as well as $C O$ itself, are required in phloem companion cells. It could also be used to revisit the question of $C O$ function outside the leaves. $C O$ mRNA has been detected by in situ hybridization at the shoot apex (Simon et al. 1996), and both reporter fusion experiments (An et al. 2004) and microarray data (Schmid et al. 2003, 2005) confirm that CO mRNA levels at the shoot apex are quite substantial.

A related question is why $C O$ mRNA peaks during the night under both long and short photoperiods, since it appears to be the earlier FKF1-dependent induction of $C O$ that is primarily responsible for the effect of long photoperiods on flowering (Suárez-López et al. 2001; Imaizumi et al. 2003). It is noticeable that all CO regulators show a circadian expression pattern. Thus, the late peak of $C O$ expression might simply be a consequence of upstream factors that are expressed in a circadian fashion, which may further point to built-in redundancy in $\mathrm{CO}$ regulation. It might be possible to address this issue by combining amiRNAs with circadian promoters, to ablate $C O$ mRNA expression during specific times of the 24-h cycle. The late peak of CO expression might also represent an atavism important in species that discriminate more finely between different daylengths than $A$. thaliana does. In this context, studies of plants that show intraspecific variation in photoperiod response are particularly promising (Böhlenius et al. 2006).

A further problem that begs more extensive study is the mechanism that underlies maintenance of the florally induced state. When $A$. thaliana plants are returned from inductive long days to noninductive short days, FT expression in leaves ceases within a day, even though the transition to flowering has been irreversibly triggered (Corbesier et al. 2007). Could the answer lie in the surprising expression pattern of FT outside the rosette leaves? After the transition to flowering, FT is most highly expressed in stem leaves on the inflorescence; in sepals, which are the green, leaf-like organs surrounding flowers; and in developing fruits and seeds (Kobayashi et al. 1999). It is noticeable that the FT repressor FLC is also highly expressed in developing seeds, but at a later stage (Schmid et al. 2005).

Finally, the CO/FT module is being redeployed by plants in other photoperiod-dependent processes, such as 


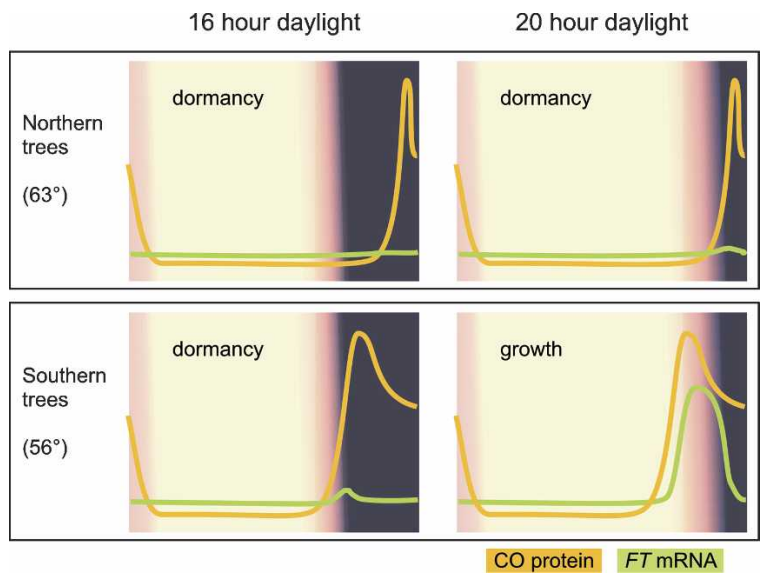

Figure 5. Latitudinal variation in CO-dependent $F T$ expression in trees. The peak of $C O$ expression is later during the day-night cycle for northern aspen trees than for southern trees. Thus, when exposed to 20 -h days, the $C O$ peak already falls into the dark for the northern trees, FT is no longer activated, and growth is not supported anymore. Conversely, the $C O$ peak for the southern trees is still in the light, FT remains active, and dormancy continues to be repressed (after data from Böhlenius et al. 2006).

tuberization in potatoes and bud dormancy in trees (Martinez-García et al. 2002; Böhlenius et al. 2006; Rodríguez-Falcón et al. 2006). The analysis of $C O$ and FT expression in aspen trees has already given very interesting new insights into the role of these factors in local adaptation. In aspen, growth ceases at the end of summer, as soon as day length falls under a critical threshold, and the plant enters dormancy. In high latitudes, such as Northern Sweden, trees need to stop growing when days are still quite long, while in temperate latitudes, such as Germany, they do so later in the year, when local days are already quite short. Ove Nilsson and colleagues (Böhlenius et al. 2006) found that $F T$ plays a critical role in this process, since it is both necessary and sufficient to promote growth. The differences in growth cessation between northern and southern trees can be explained by variation in the relative peak of $C O$ mRNA expression during the day-night cycle, such that southern trees have an earlier peak than northern trees, independently of external photoperiod (Fig. 5; Böhlenius et al. 2006). Apart from being interesting in its own right, identification of downstream elements that provide specificity in processes such as bud dormancy and tuberization should in turn also inform our understanding of floral induction. The field of photoperiodic control of plant development will certainly continue to flower for years.

\section{Acknowledgments}

We apologize to our colleagues whose studies have not been cited because of space constraints, or whose work has not been properly discussed in this highly subjective review. We thank Emiko Kobayashi for kind help with figures, and Sascha Laubinger, François Parcy, Patrice Salomé, Markus Schmid, and three anonymous reviewers for insightful comments. Our work on flowering has been supported by HFSPO and JSPS (Y.K.) and by the Max Planck Society, of which D.W. is a Director.

\section{References}

Abe, M., Kobayashi, Y., Yamamoto, S., Daimon, Y., Yamaguchi, A., Ikeda, Y., Ichinoki, H., Notaguchi, M., Goto, K., and Araki, T. 2005. FD, a bZIP protein mediating signals from the floral pathway integrator FT at the shoot apex. Science 309: 1052-1056.

Ahn, J.H., Miller, D., Winter, V.J., Banfield, M.J., Lee, J.H., Yoo, S.Y., Henz, S.R., Brady, R.L., and Weigel, D. 2006. A divergent external loop confers antagonistic activity on floral regulators FT and TFL1. EMBO J. 25: 605-614.

Alvarez, J.P., Pekker, I., Goldshmidt, A., Blum, E., Amsellem, Z., and Eshed, Y. 2006. Endogenous and synthetic microRNAs stimulate simultaneous, efficient, and localized regulation of multiple targets in diverse species. Plant Cell 18: 1134-1151.

An, H., Roussot, C., Suárez-López, P., Corbesier, L., Vincent, C., Piñeiro, M., Hepworth, S., Mouradov, A., Justin, S., Turnbull, C., et al. 2004. CONSTANS acts in the phloem to regulate a systemic signal that induces photoperiodic flowering of Arabidopsis. Development 131: 3615-3626.

Aukerman, M.J. and Sakai, H. 2003. Regulation of flowering time and floral organ identity by a microRNA and its APETALA2-like target genes. Plant Cell 15: 2730-2741.

Ayre, B.G. and Turgeon, R. 2004. Graft transmission of a floral stimulant derived from CONSTANS. Plant Physiol. 135: 2271-2278.

Bäckström, S., Elfving, N., Nilsson, R., Wingsle, G., and Björklund, S. 2007. Purification of a plant mediator from Arabidopsis thaliana identifies PFT1 as the Med25 subunit. Mol. Cell 26: 717-729.

Ben-Naim, O., Eshed, R., Parnis, A., Teper-Bamnolker, P., Shalit, A., Coupland, G., Samach, A., and Lifschitz, E. 2006. The CCAAT binding factor can mediate interactions between CONSTANS-like proteins and DNA. Plant J. 46: 462-476.

Blázquez, M.A. and Weigel, D. 2000. Integration of floral inductive signals in Arabidopsis. Nature 404: 889-892.

Blázquez, M.A., Green, R., Nilsson, O., Sussman, M.R., and Weigel, D. 1998. Gibberellins promote flowering of Arabidopsis by activating the $L E A F Y$ promoter. Plant Cell 10: 791-800.

Blázquez, M.A., Trénor, M., and Weigel, D. 2002. Independent control of gibberellin biosynthesis and flowering time by the circadian clock in Arabidopsis. Plant Physiol. 130: 17701775.

Böhlenius, H., Huang, T., Charbonnel-Campaa, L., Brunner, A.M., Jansson, S., Strauss, S.H., and Nilsson, O. 2006. CO/ FT regulatory module controls timing of flowering and seasonal growth cessation in trees. Science 312: 1040-1043.

Borner, R., Kampmann, G., Chandler, J., Gleissner, R., Wisman, E., Apel, K., and Melzer, S. 2000. A MADS domain gene involved in the transition to flowering in Arabidopsis. Plant J. 24: 591-599.

Bünning, E. 1936. Die endogene Tagesrhythmik als Grundlage der photoperiodischen Reaktion. Ber. Dt. Botan. Ges. 54: 590-607.

Bünning, E. and Stern, K. 1930. Über die tagesperiodischen Bewegungen der Primärblätter von Phaseolus multiflorus. II. Die Bewegungen bei Thermokonstanz. Ber. Dt. Botan. Ges. 48: 227-252.

Cai, X., Ballif, J., Endo, S., Davis, E., Liang, M., Chen, D., Dewald, D., Kreps, J., Zhu, T., and $\mathrm{Wu}$, Y. 2007. A putative CCAAT-binding transcription factor is a regulator of flow- 
ering timing in Arabidopsis. Plant Physiol. doi: 10.1104/ pp.1107.102079.

Cerdán, P.D. and Chory, J. 2003. Regulation of flowering time by light quality. Nature 423: $881-885$.

Chailakhyan, M.K. 1936a. [About the mechanism of the photoperiodic response.] (in Russian) Dokl. Akad. Nauk SSSR (C. R. Acad. Sci. USSR) 1: 85-89.

Chailakhyan, M.K. 1936b. [New facts supporting the hormonal theory of plant development.] (in Russian) Dokl. Akad. Nauk SSSR (C. R. Acad. Sci. USSR) 4: 77-81.

Chailakhyan, M.K. 1937. Gormonal'naya teoriya razvitiya rastenii [Hormonal theory of plant development]. Akademii Nauk SSSR (Academy of Sciences of the USSR), Moscow.

Chen, X. 2004. A microRNA as a translational repressor of APETALA2 in Arabidopsis flower development. Science 303: 2022-2025.

Chen, M. and Ni, M. 2006. RFI2, a RING-domain zinc finger protein, negatively regulates CONSTANS expression and photoperiodic flowering. Plant T. 46: 823-833.

Corbesier, L., Vincent, C., Jang, S., Fornara, F., Fan, Q., Searle, I., Giakountis, A., Farrona, S., Gissot, L., Turnbull, C., et al. 2007. FT protein movement contributes to long-distance signaling in floral induction of Arabidopsis. Science 316: 10301033.

Cui, H., Levesque, M.P., Vernoux, T., Jung, J.W., Paquette, A.J., Gallagher, K.L., Wang, J.Y., Blilou, I., Scheres, B., and Benfey, P.N. 2007. An evolutionarily conserved mechanism delimiting SHR movement defines a single layer of endodermis in plants. Science 316: 421-425.

de Folter, S., Immink, R.G., Kieffer, M., Paenicová, L., Henz, S.R., Weigel, D., Busscher, M., Kooiker, M., Colombo, L., Kater, M.M., et al. 2005. Comprehensive interaction map of the Arabidopsis MADS box transcription factors. Plant Cell 17: 1424-1433.

Doi, K., Izawa, T., Fuse, T., Yamanouchi, U., Kubo, T., Shimatani, Z., Yano, M., and Yoshimura, A. 2004. Ehd1, a B-type response regulator in rice, confers short-day promotion of flowering and controls FT-like gene expression independently of Hd1. Genes \& Dev. 18: 926-936.

Endo, M., Nakamura, S., Araki, T., Mochizuki, N., and Nagatani, A. 2005. Phytochrome B in the mesophyll delays flowering by suppressing FLOWERING LOCUS T expression in Arabidopsis vascular bundles. Plant Cell 17: 1941-1952.

Eriksson, S., Böhlenius, H., Moritz, T., and Nilsson, O. 2006. $\mathrm{GA}_{4}$ is the active gibberellin in the regulation of $L E A F Y$ transcription and Arabidopsis floral initiation. Plant Cell 18: $2172-2181$

Fujiwara, S., Oda, A., Kamada, H., Coupland, G., and Mizoguchi, T. 2005. Circadian clock components in Arabidopsis. II. LHY/CCA regulate the floral integrator gene SOC1 in both GI-dependent and -independent pathways. Plant Biotechnol. 22: 319-325

Gardner, M.J., Hubbard, K.E., Hotta, C.T., Dodd, A.N., and Webb, A.A. 2006. How plants tell the time. Biochem. J. 397: $15-24$.

Garner, W.W. and Allard, H.A. 1920. Effect of the relative length of day and night and other factors of the environment on growth and reproduction in plants. J. Agric. Res. 18: 553606.

Garner, W.W. and Allard, H.A. 1923. Further studies on photoperiodism, the response of plants to relative length of day and night. J. Agric. Res. 23: 871-920.

Germann, S., Juul-Jensen, T., Letarnec, B., and Gaudin, V. 2006. DamID, a new tool for studying plant chromatin profiling in vivo, and its use to identify putative LHP1 target loci. Plant J. 48: 153-163.
Giavalisco, P., Kapitza, K., Kolasa, A., Buhtz, A., and Kehr, J. 2006. Towards the proteome of Brassica napus phloem sap. Proteomics 6: 896-909.

Griffiths, J., Murase, K., Rieu, I., Zentella, R., Zhang, Z.L., Powers, S.J., Gong, F., Phillips, A.L., Hedden, P., Sun, T.P., et al. 2006. Genetic characterization and functional analysis of the GID1 gibberellin receptors in Arabidopsis. Plant Cell 18: 3399-3414.

Guo, H., Yang, H., Mockler, T.C., and Lin, C. 1998. Regulation of flowering time by Arabidopsis photoreceptors. Science 279: 1360-1363.

Halliday, K.J., Salter, M.G., Thingnaes, E., and Whitelam, G.C. 2003. Phytochrome control of flowering is temperature sensitive and correlates with expression of the floral integrator FT. Plant J. 33: 875-885.

Hamner, K.C. and Bonner, J. 1938. Photoperiodism in relation to hormones as factors in floral initiation and development. Bot. Gaz. 100: 388-431.

Han, L., Mason, M., Risseeuw, E.P., Crosby, W.L., and Somers, D.E. 2004. Formation of an SCF ${ }^{Z T L}$ complex is required for proper regulation of circadian timing. Plant J. 40: 291-301.

Harder, R. and Bode, O. 1943. Über die Wirkung von Zwischenbelichtungen während der Dunkelperiode auf das Blühen, die Verlaubung und die Blattsukkulenz bei der Kurztagspflanze Kalanchoë bloßfeldiana. Planta 33: 469-504.

Harmer, S.L., Hogenesch, J.B., Straume, M., Chang, H.S., Han, B., Zhu, T., Wang, X., Kreps, J.A., and Kay, S.A., 2000. Orchestrated transcription of key pathways in Arabidopsis by the circadian clock. Science 290: 2110-2113.

Hayama, R., Yokoi, S., Tamaki, S., Yano, M., and Shimamoto, K. 2003. Adaptation of photoperiodic control pathways produces short-day flowering in rice. Nature 422: 719-722.

Heisler, M.G., Ohno, C., Das, P., Sieber, P., Reddy, G.V., Long, J.A., and Meyerowitz, E.M. 2005. Patterns of auxin transport and gene expression during primordium development revealed by live imaging of the Arabidopsis inflorescence meristem. Curr. Biol. 15: 1899-1911.

Helliwell, C.A., Wood, C.C., Robertson, M., Peacock, W.J., and Dennis, E.S. 2006. The Arabidopsis FLC protein interacts directly in vivo with SOC1 and FT chromatin and is part of a high-molecular-weight protein complex. Plant J. 46: 183192.

Henfrey, A. 1852. The vegetation of Europe, its conditions and causes. J. Van Voorst, London.

Hepworth, S.R., Valverde, F., Ravenscroft, D., Mouradov, A. and Coupland, G. 2002. Antagonistic regulation of flowering-time gene SOC1 by CONSTANS and FLC via separate promoter motifs. EMBO J. 21: 4327-4337.

Imaizumi, T., Tran, H.G., Swartz, T.E., Briggs, W.R., and Kay, S.A. 2003. FKF1 is essential for photoperiodic-specific light signalling in Arabidopsis. Nature 426: 302-306.

Imaizumi, T., Schultz, T.F., Harmon, F.G., Ho, L.A., and Kay, S.A. 2005. FKF1 F-box protein mediates cyclic degradation of a repressor of CONSTANS in Arabidopsis. Science 309: 293 297.

Imamura, S. 1967. Photoperiodic induction and the floral stimulus. In Physiology of flowering in Pharbitis nil (ed. S. Imamura), pp. 15-28. Japanese Society of Plant Physiologists, Tokyo.

Imlau, A., Truernit, E., and Sauer, N. 1999. Cell-to-cell and long-distance trafficking of the green fluorescent protein in the phloem and symplastic unloading of the protein into sink tissues. Plant Cell 11: 309-322.

Ishikawa, R., Tamaki, S., Yokoi, S., Inagaki, N., Shinomura, T., Takano, M., and Shimamoto, K. 2005. Suppression of the floral activator $H d 3 a$ is the principal cause of the night break 
effect in rice. Plant Cell 17: 3326-3336.

Izawa, T., Oikawa, T., Sugiyama, N., Tanisaka, T., Yano, M., and Shimamoto, K. 2002. Phytochrome mediates the external light signal to repress $F T$ orthologs in photoperiodic flowering of rice. Genes \& Dev. 16: 2006-2020.

Jaeger, K.E. and Wigge, P.A. 2007. FT protein acts as a long-range signal in Arabidopsis. Curr. Biol. 17: 1050-1054.

Jorgensen, R.A., Atkinson, R.G., Forster, R.L.S., and Lucas, W.J. 1998. An RNA-based information superhighway in plants. Science 279: 1486-1487.

Kardailsky, I., Shukla, V., Ahn, J.H., Dagenais, N., Christensen, S.K., Nguyen, J.T., Chory, J., Harrison, M.J., and Weigel, D. 1999. Activation tagging of the floral inducer FT. Science 286: $1962-1965$.

Karege, F., Penel, C., and Greppin, H. 1982. Détection de l'état végétatif et floral de la feuille de l'épinard: Emploi d'un indicateur biochimique. Arch. Sci. Genève 35: 331-340.

King, R.W., Evans, L.T., and Wardlaw, I.F. 1968. Translocation of the floral stimulus in Pharbitis nil in relation to that of assimilates. Z. Pflanzenphysiol. 59: 377-388.

King, R.W., Moritz, T., Evans, L.T., Martin, J., Andersen, C.H., Blundell, C., Kardailsky, I., and Chandler, P.M. 2006. Regulation of flowering in the long-day grass Lolium temulentum by gibberellins and the FLOWERING LOCUS T gene. Plant Physiol. 141: 498-507.

Klebs, G. 1913. Über das Verhältnis der Außenwelt zur Entwicklung der Pflanze. Sitzber. Akad. Wiss. Heidelberg B 5: $1-47$.

Knott, J.E. 1934. Effect of a localized photoperiod on spinach. Proc. Am. Soc. Hortic. Sci. 31 (Suppl.): 152-154.

Kobayashi, Y., Kaya, H., Goto, K., Iwabuchi, M., and Araki, T. 1999. A pair of related genes with antagonistic roles in mediating flowering signals. Science 286: 1960-1962.

Kojima, S., Takahashi, Y., Kobayashi, Y., Monna, L., Sasaki, T., Araki, T., and Yano, M. 2002. Hd3a, a rice ortholog of the Arabidopsis FT gene, promotes transition to flowering downstream of Hd1 under short-day conditions. Plant Cell Physiol. 43: 1096-1105.

Koornneef, M., Hanhart, C.J., and van der Veen, J.H. 1991. A genetic and physiological analysis of late flowering mutants in Arabidopsis thaliana. Mol. Gen. Genet. 229: 57-66.

Laibach, F. 1951. Über sommer- und winterannuelle Rassen von Arabidopsis thaliana (L.) Heynh. Ein Beitrag zur Ätiologie der Blütenbildung. Beitr. Biol. Pflanzen 28: 173-210.

Lang, A. and Melchers, G. 1948. Auslösung der Blütenbildung bei Langtagpflanzen in Kurztagbedingungen durch Aufpfropfung von Kurztagpflanzen. Z. Naturforsch. 3b: 108-111.

Laubinger, S., Fittinghoff, K., and Hoecker, U. 2004. The SPA quartet: A family of WD-repeat proteins with a central role in suppression of photomorphogenesis in Arabidopsis. Plant Cell 16: 2293-2306.

Laubinger, S., Marchal, V., Gentilhomme, J., Wenkel, S., Adrian, J., Jang, S., Kulajta, C., Braun, H., Coupland, G., and Hoecker, U. 2006. Arabidopsis SPA proteins regulate photoperiodic flowering and interact with the floral inducer CONSTANS to regulate its stability. Development 133: 32133222.

Lee, H., Suh, S.S., Park, E., Cho, E., Ahn, J.H., Kim, S.G., Lee, J.S., Kwon, Y.M., and Lee, I. 2000. The AGAMOUS-LIKE 20 MADS domain protein integrates floral inductive pathways in Arabidopsis. Genes \& Dev. 14: 2366-2376.

Lee, J.H., Yoo, S.J., Park, S.H., Hwang, I., Lee, J.S., and Ahn, J.H. 2007. Role of SVP in the control of flowering time by ambient temperature in Arabidopsis. Genes \& Dev. 21: 397-402.

Lifschitz, E., Eviatar, T., Rozman, A., Shalit, A., Goldshmidt, A., Amsellem, Z., Alvarez, J.P., and Eshed, Y. 2006. The tomato
FT ortholog triggers systemic signals that regulate growth and flowering and substitute for diverse environmental stimuli. Proc. Natl. Acad. Sci. 103: 6398-6403.

Lin, M.K., Belanger, H., Lee, Y.J., Varkonyi-Gasic, E., Taoka, K.I., Miura, E., Xoconostle-Cázares, B., Gendler, K., Jorgensen, R.A., Phinney, B., et al. 2007. FLOWERING LOCUS $\mathrm{T}$ protein may act as the long-distance florigenic signal in the cucurbits. Plant Cell 19: 1488-1506.

Liu, C., Zhou, J., Bracha-Drori, K., Yalovsky, S., Ito, T., and Yu, H. 2007. Specification of Arabidopsis floral meristem identity by repression of flowering time genes. Development 134: 1901-1910.

Locke, J.C., Kozma-Bognár, L., Gould, P.D., Fehér, B., Kevei, E., Nagy, F., Turner, M.S., Hall, A., and Millar, A.J. 2006. Experimental validation of a predicted feedback loop in the multi-oscillator clock of Arabidopsis thaliana. Mol. Syst. Biol. 2: 59. doi: $10.1038 / \mathrm{msb} 4100102$.

Martinez-García, J.F., Virgós-Soler, A., and Prat, S. 2002. Control of photoperiod-regulated tuberization in potato by the Arabidopsis flowering-time gene CONSTANS. Proc. Natl. Acad. Sci. 99: 15211-15216.

Mathieu, J., Warthmann, N., Küttner, F., and Schmid, M. 2007. Export of FT protein from phloem companion cells is sufficient for floral induction in Arabidopsis. Curr. Biol. 17: $1055-1060$.

McClung, C.R. 2006. Plant circadian rhythms. Plant Cell 18: 792-803

Melchers, G. 1937. Die Wirkung von Genen, tiefen Temperaturen und blühenden Propfpartnern auf die Blühreife von Hyoscyamus. Biol. Zbl. 57: 568-614.

Michaels, S.D., Himelblau, E., Kim, S.Y., Schomburg, F.M., and Amasino, R.M. 2005. Integration of flowering signals in winter-annual Arabidopsis. Plant Physiol. 137: 149-156.

Millar, A.J., Carré, I.A., Strayer, C.A., Chua, N.H., and Kay, S.A. 1995. Circadian clock mutants in Arabidopsis identified by luciferase imaging. Science 267: 1161-1163.

Mockler, T., Yang, H., Yu, X., Parikh, D., Cheng, Y.C., Dolan, S., and Lin, C. 2003. Regulation of photoperiodic flowering by Arabidopsis photoreceptors. Proc. Natl. Acad. Sci. 100: 2140-2145.

Moon, J., Suh, S.S., Lee, H., Choi, K.R., Hong, C.B., Paek, N.C., Kim, S.G., and Lee, I. 2003. The SOC1 MADS-box gene integrates vernalization and gibberellin signals for flowering in Arabidopsis. Plant J. 35: 613-623.

Moon, J., Lee, H., Kim, M., and Lee, I. 2005. Analysis of flowering pathway integrators in Arabidopsis. Plant Cell Physiol. 46: 292-299.

Nanda, K.K. and Hamner, K.C. 1958. Studies on the nature of the endogenous rhythm affecting photoperiodic response of Biloxi soybean. Bot. Gaz. 120: 14-25.

Napp-Zinn, K. 1969. Arabidopsis thaliana (L.) Heynh. In The induction of flowering: Some case histories (ed. L.T. Evans), pp. 291-304. MacMillan, Melbourne. Australia.

Naylor, A.W. 1941. Effect of nutrition and age upon rate of development of terminal staminate inflorescences of Xanthium pennsylvanicum. Bot. Gaz. 103: 342-353.

Nilsson, O., Lee, I., Blázquez, M.A., and Weigel, D. 1998. Flowering-time genes modulate the response to LEAFY activity. Genetics 150: 403-410.

Pharis, R.P., Evans, L.T., King, R.W., and Mander, L.N. 1987. Gibberellins, endogenous and applied, in relation to flower induction in the long-day plant Lolium temulentum. Plant Physiol. 84: 1132-1138.

Piñeiro, M., Gómez-Mena, C., Schaffer, R., Martínez-Zapater, J.M., and Coupland, G. 2003. EARLY BOLTING IN SHORT DAYS is related to chromatin remodeling factors and regu- 
lates flowering in Arabidopsis by repressing FT. Plant Cell 15: $1552-1562$.

Pittendrigh, C.S. 1960. Circadian rhythms and the circadian organization of living systems. Cold Spring Harb. Symp. Quant. Biol. 25: 159-184.

Pittendrigh, C.S. 1972. Circadian surfaces and the diversity of possible roles of circadian organization in photoperiodic induction. Proc. Natl. Acad. Sci. 69: 2734-2737.

Pittendrigh, C.S. and Minis, D.H. 1964. The entrainment of circadian oscillations by light and their role as photoperiodic clocks. Am. Nat. 98: 261-294.

Pnueli, L., Gutfinger, T., Hareven, D., Ben-Naim, O., Ron, N., Adir, N., and Lifschitz, E. 2001. Tomato SP-interacting proteins define a conserved signaling system that regulates shoot architecture and flowering. Plant Cell 13: 2687-2702.

Putterill, J., Robson, F., Lee, K., Simon, R., and Coupland, G. 1995. The CONSTANS gene of Arabidopsis promotes flowering and encodes a protein showing similarities to zinc finger transcription factors. Cell 80: 847-857.

Rédei, G.P. 1962. Supervital mutants of Arabidopsis. Genetics 47: 443-460.

Reed, J.W., Nagpal, P., Poole, D.S., Furuya, M., and Chory, J. 1993. Mutations in the gene for the red/far-red light receptor phytochrome B alter cell elongation and physiological responses throughout Arabidopsis development. Plant Cell 5: $147-157$.

Reeves, P.H. and Coupland, G. 2001. Analysis of flowering time control in Arabidopsis by comparison of double and triple mutants. Plant Physiol. 126: 1085-1091.

Roden, L.C., Song, H.R., Jackson, S., Morris, K., and Carré, I.A. 2002. Floral responses to photoperiod are correlated with the timing of rhythmic expression relative to dawn and dusk in Arabidopsis. Proc. Natl. Acad. Sci. 99: 13313-13318.

Rodríguez-Falcón, M., Bou, J., and Prat, S. 2006. Seasonal control of tuberization in potato: Conserved elements with the flowering response. Annu. Rev. Plant Biol. 57: 151-180.

Ruiz-García, L., Madueño, F., Wilkinson, M., Haughn, G., Salinas, J., and Martínez-Zapater, J.M. 1997. Different roles of flowering time genes in the activation of floral initiation genes in Arabidopsis. Plant Cell 9: 1921-1934.

Sachs, J. 1865. Handbuch der Experimentalphysiologie der Pflanzen. W. Engelmann, Leipzig, Germany.

Samach, A., Onouchi, H., Gold, S.E., Ditta, G.S., Schwarz-Sommer, Z., Yanofsky, M.F., and Coupland, G. 2000. Distinct roles of CONSTANS target genes in reproductive development of Arabidopsis. Science 288: 1613-1616.

Schmid, M., Uhlenhaut, N.H., Godard, F., Demar, M., Bressan, R., Weigel, D., and Lohmann, J.U. 2003. Dissection of floral induction pathways using global expression analysis. Development 130: 6001-6012.

Schmid, M., Davison, T.S., Henz, S.R., Pape, U.J., Demar, M., Vingron, M., Schölkopf, B., Weigel, D., and Lohmann, J.U. 2005. A gene expression map of Arabidopsis thaliana development. Nat. Genet. 37: 501-506.

Schwab, R., Palatnik, J.F., Riester, M., Schommer, C., Schmid, M., and Weigel, D. 2005. Specific effects of microRNAs on the plant transcriptome. Dev. Cell 8: 517-527.

Schwab, R., Ossowski, S., Riester, M., Warthmann, N., and Weigel, D. 2006. Highly specific gene silencing by artificial microRNAs in Arabidopsis. Plant Cell 18: 1121-1133.

Searle, I., He, Y., Turck, F., Vincent, C., Fornara, F., Krober, S., Amasino, R.A., and Coupland, G. 2006. The transcription factor FLC confers a flowering response to vernalization by repressing meristem competence and systemic signaling in Arabidopsis. Genes \& Dev. 20: 898-912.

Simon, R., Igeño, M.I., and Coupland, G. 1996. Activation of floral meristem identity genes in Arabidopsis. Nature 382: 59-62.

Stadler, R., Wright, K.M., Lauterbach, C., Amon, G., Gahrtz, M., Feuerstein, A., Oparka, K.J., and Sauer, N. 2005. Expression of GFP-fusions in Arabidopsis companion cells reveals nonspecific protein trafficking into sieve elements and identifies a novel post-phloem domain in roots. Plant J. 41: 319-331.

Strayer, C., Oyama, T., Schultz, T.F., Raman, R., Somers, D.E., Mas, P., Panda, S., Kreps, J.A., and Kay, S.A. 2000. Cloning of the Arabidopsis clock gene TOC1, an autoregulatory response regulator homolog. Science 289: 768-771.

Suárez-López, P., Wheatley, K., Robson, F., Onouchi, H., Valverde, F., and Coupland, G. 2001. CONSTANS mediates between the circadian clock and the control of flowering in Arabidopsis. Nature 410: 1116-1120.

Takada, S. and Goto, K. 2003. TERMINAL FLOWER2, an Arabidopsis homolog of HETEROCHROMATIN PROTEIN1, counteracts the activation of FLOWERING LOCUS $T$ by CONSTANS in the vascular tissues of leaves to regulate flowering time. Plant Cell 15: 2856-2865.

Takahashi, N., Kuroda, H., Kuromori, T., Hirayama, T., Seki, M., Shinozaki, K., Shimada, H., and Matsui, M. 2004. Expression and interaction analysis of Arabidopsis Skp1-related genes. Plant Cell Physiol. 45: 83-91.

Tamaki, S., Matsuo, S., Wong, H.L., Yokoi, S., and Shimamoto, K. 2007. Hd3a protein is a mobile flowering signal in rice. Science 316: 1033-1036.

Teper-Bamnolker, P. and Samach, A. 2005. The flowering integrator FT regulates SEPALLATA3 and FRUITFULL accumulation in Arabidopsis leaves. Plant Cell 17: 2661-2675.

Thomas, B. and Vince-Prue, D. 1997. Photoperiodism in plants. Academic Press, New York.

Tournois, J. 1912. Influence de la lumière sur la floraison du houblon japonais et du chanvre déterminées par des semis haitifs. C. R. Acad. Sci. Paris 155: 297-300.

Turck, F., Roudier, F., Farrona, S., Martin-Magniette, M.L., Guillaume, E., Buisine, N., Gagnot, S., Martienssen, R.A., Coupland, G., and Colot, V. 2007. Arabidopsis TFL2/LHP1 specifically associates with genes marked by trimethylation of histone H3 lysine 27. PLoS Genet. 3: e86. doi: 10.1371/ journal.pgen.0030086.

Valverde, F., Mouradov, A., Soppe, W., Ravenscroft, D., Samach, A., and Coupland, G. 2004. Photoreceptor regulation of CONSTANS protein in photoperiodic flowering. Science 303: 1003-1006.

Weigel, D., Alvarez, J., Smyth, D.R., Yanofsky, M.F., and Meyerowitz, E.M. 1992. LEAFY controls floral meristem identity in Arabidopsis. Cell 69: 843-859.

Wenkel, S., Turck, F., Singer, K., Gissot, L., Le Gourrierec, J., Samach, A., and Coupland, G. 2006. CONSTANS and the CCAAT box binding complex share a functionally important domain and interact to regulate flowering of Arabidopsis. Plant Cell 18: 2971-2984.

Wigge, P.A., Kim, M.C., Jaeger, K.E., Busch, W., Schmid, M., Lohmann, J.U., and Weigel, D. 2005. Integration of spatial and temporal information during floral induction in Arabidopsis. Science 309: 1056-1059.

Willige, B.C., Ghosh, S., Nill, C., Zourelidou, M., Dohmann, E.M., Maier, A., and Schwechheimer, C. 2007. The DELLA domain of GA INSENSITIVE mediates the Interaction with the GA INSENSITIVE DWARF1A gibberellin receptor of Arabidopsis. Plant Cell 19: 1209-1220.

Wu, X., Dinneny, J.R., Crawford, K.M., Rhee, Y., Citovsky, V., Zambryski, P.C., and Weigel, D. 2003. Modes of intercellular transcription factor movement in the Arabidopsis apex. Development 130: 3735-3745. 
Yamaguchi, A., Kobayashi, Y., Goto, K., Abe, M., and Araki, T. 2005. TWIN SISTER OF FT (TSF) acts as a floral pathway integrator redundantly with FT. Plant Cell Physiol. 46: 1175-1189.

Yano, M., Katayose, Y., Ashikari, M., Yamanouchi, U., Monna, L., Fuse, T., Baba, T., Yamamoto, K., Umehara, Y., Nagamura, Y., et al. 2000. Hd1, a major photoperiod sensitivity Quantitative Trait Locus in rice, is closely related to the Arabidopsis flowering-time gene CONSTANS. Plant Cell 12: 2473-2483.

Yanovsky, M.J. and Kay, S.A. 2002. Molecular basis of seasonal time measurement in Arabidopsis. Nature 419: 308-312.

Yoo, B.C., Kragler, F., Varkonyi-Gasic, E., Haywood, V., ArcherEvans, S., Lee, Y.M., Lough, T.J., and Lucas, W.J. 2004. A systemic small RNA signaling system in plants. Plant Cell 16: $1979-2000$.

Yoo, S.K., Chung, K.S., Kim, J., Lee, J.H., Hong, S.M., Yoo, S.J., Yoo, S.Y., Lee, J.S., and Ahn, J.H. 2005. CONSTANS activates SUPPRESSOR OF OVEREXPRESSION OF CONSTANS 1 through FLOWERING LOCUS T to promote flowering in Arabidopsis. Plant Physiol. 139: 770-778.

$\mathrm{Yu}, \mathrm{H} ., \mathrm{Xu}, \mathrm{Y} .$, Tan, E.L., and Kumar, P.P. 2002. AGAMOUS LIKE 24, a dosage-dependent mediator of the flowering signals. Proc. Natl. Acad. Sci. 99: 16336-16341.

Yu, H., Ito, T., Wellmer, F., and Meyerowitz, E.M. 2004. Repression of AGAMOUS-LIKE 24 is a crucial step in promoting flower development. Nat. Genet. 36: 157-161.

Zeevaart, J.A.D. 1958. Flower formation as studied by grafting. Meded. Landbouwhogesch. Wageningen 58: 1-88.

Zeevaart, J.A. 2006. Florigen coming of age after 70 years. Plant Cell 18: 1783-1789.

Zeilinger, M.N., Farré, E.M., Taylor, S.R., Kay, S.A., and Doyle III, F.J. 2006. A novel computational model of the circadian clock in Arabidopsis that incorporates PRR7 and PRR9. Mol. Syst. Biol. 2: 58. doi: 10.1038/msb4100101. 


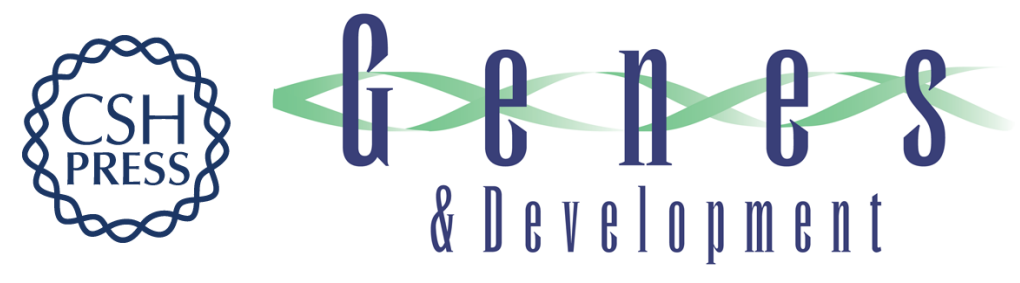

\section{Move on up, it's time for change--mobile signals controlling photoperiod-dependent flowering}

Yasushi Kobayashi and Detlef Weigel

Genes Dev. 2007, 21:

Access the most recent version at doi:10.1101/gad.1589007

References This article cites 126 articles, 71 of which can be accessed free at: http://genesdev.cshlp.org/content/21/19/2371.full.html\#ref-list-1

License

Email Alerting

Receive free email alerts when new articles cite this article - sign up in the box at the top Service right corner of the article or click here.

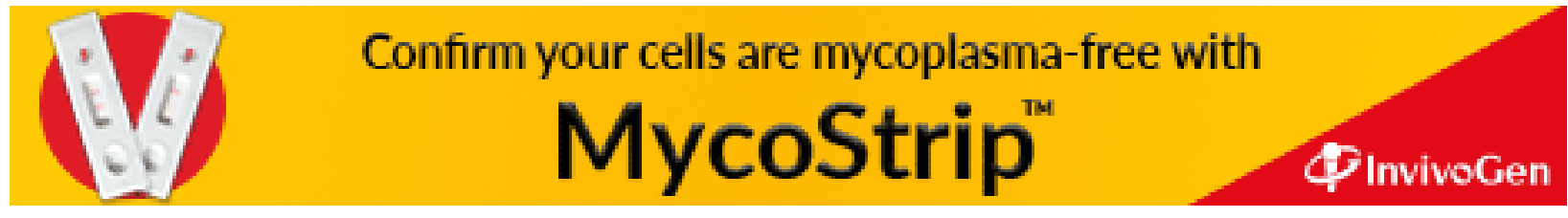

